Teknokultura. Revista de Cultura Digital y Movimientos Sociales ISSNe: $1549-2230$

\title{
Reseña/Review (Srnicek, Nick, "Capitalismo de plataformas", Buenos Aires: Caja Negra, ISBN: 978-987-1622-68-9, 128 págs., 2018)
}

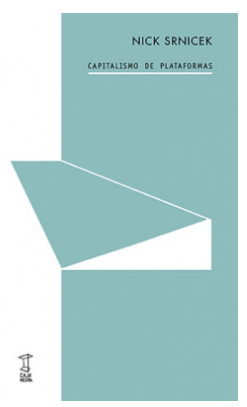

Sharing economy, consumo colaborativo, economía peer-topeer... son términos que desde hace algunos años parecen anunciar una auténtica revolución económica. De alguna manera la aparición de nuevos servicios disponibles desde plataformas digitales (Uber, Airbnb e, incluso, Facebook) parece haber cambiado el paradigma económico del capitalismo tal y como lo conocíamos. Según este relato, las plataformas digitales simplemente median y agilizan relaciones sociales que "ya estaban allí"; la gente siempre ha compartido el coche para ir al trabajo, pero ahora con Uber todo es mucho más sencillo, directo y al alcance de todo el mundo. La digitalización de la economía desmaterializará el trabajo y transformará al antiguo proletariado en un cognitariado, que pasará a depender de su capacidad para gestionar información y producir servicios culturales. Sin embargo, su desarrollo no ha estado exento de controversias, desde la afición de las empresas de la economía digital a la evasión fiscal hasta el desarrollo de modelos laborales (la famosa gig economy) que llevan la precariedad y la explotación a niveles que nadie hubiese creído posibles en el contexto de países occidentales con democracias consolidadas. Las promesas de superación de los costes morales del capitalismo parecen haber encontrado serios obstáculos que plantean numerosos interrogantes acerca de las características de esta "nueva economía".

Capitalismo de plataformas trata de responder algunas de estas cuestiones a través de una concisa taxonomía de las condiciones económicas que han hecho posible y en las que se desenvuelven las principales empresas de la economía digital. La idea principal que estructura todo el hilo argumentativo de los tres capítulos del libro, es que la mejor manera de entender la economía digital es reintroducirla dentro de la dinámica general del capitalismo. Las plataformas digitales operan como actores económicos en busca de ganancias, para lo cual deben constantemente abrir mercados y consolidarlos ahuyentando a la competencia. Frente a los análisis basados en los discursos y narrativas ideológicas que existen alrededor de este fenómeno, Srnicek propone un análisis materialista anclado, básicamente, en los procesos económicos.

El primer capítulo del libro trata de dar cuenta del giro del capitalismo hacia el formato de la plataforma y las tecnologías digitales. Srnicek plantea que, de alguna manera, la crisis de los años setenta marca el declive de un modelo de capitalismo basado en la rentabilidad de la producción de manufacturas. La contestación por parte de Alemania y Japón a la hegemonía industrial estadounidense se tradujo en una sobrecapacidad y sobreproducción de las manufacturas que devino en una bajada generalizada de los precios. Estos procesos convivieron con el comienzo de 
la comercialización de Internet, haciendo de las empresas de telecomunicaciones oportunidades de negocio muy suculentas para la obtención de altas tasas de rentabilidad en las inversiones. El aumento espectacular en las transacciones financieras y la tecnología de telecomunicaciones estimuló la creación de burbujas financieras y el aumento exponencial en los procesos de tercerización en los sectores económicos tradicionales. El resultado no se hace esperar y a principios de 1052000 y en 2008 pinchan las burbujas, obligando a intervenciones públicas que disparan el déficit de los Estados a cotas estratosféricas. Maniatados por la ideología neoliberal de restricción del gasto público, los Estados se ven obligados a recurrir a intervenciones muy poco ortodoxas para poder recuperar el crecimiento en la economía. Estas medidas liberan una gran cantidad de efectivo al mismo tiempo que reducen la tasa de retorno de las inversiones convencionales, orientando a los inversores a operaciones de mucho más riesgo: como, por ejemplo, tecnologías nuevas. Lo que la "ideología californiana" presenta como el descubrimiento de formas novedosas de negocio por parte de un puñado de emprendedores iluminados en un espacio de completa libertad empresarial se revela como lo contrario; una suerte de "keynesianismo financiero" de consecuencias devastadoras, tanto para las administraciones públicas como para los derechos de los trabajadores.

El segundo capítulo es una descripción de la especificidad del modelo de negocio de las plataformas digitales, que acaba clasificando en una tipología según el tipo de actividad que llevan a cabo. En este sentido, lo verdaderamente específico del capitalismo del siglo XXI sería haber descubierto los datos como materia prima. La mayor parte de la actividad de estas empresas consiste en la recolección y procesamiento de datos, cuantos más y más variados mejor. La plataforma es en realidad el modo de organización más eficiente para la recolección de datos, y su ascenso a forma privilegiada de organización empresarial tiene que ver con cada vez mayor valor de esos datos. La plataforma provee el ecosistema mismo en donde tienen lugar las diferentes actividades; todo lo que se haga tiene que pasar necesariamente por su infraestructura. Este hecho convierte a las plataformas literalmente en "minas de datos", que después las empresas rentabilizarán según su sector de actividad. Las plataformas "en la nube" como Google o Facebook los utilizan para alquilar a otras empresas su potente maquinaria de análisis y vender publicidad hiperespecializada. Otras empresas, como Amazon, GE, y Siemens los utilizan para radicalizar el modelo taylorista de producción, en términos de maximización extrema de la eficiencia productiva; las smart factories utilizan análisis de datos para reducir al mínimo los tiempos muertos, los recursos desperdiciados y maximizar la utilidad de la energía. Otras plataformas, como Uber, de rentabilidad más dudosa, los utilizan para aventajar a la competencia. Sin embargo, el interés principal de Srnicek pasa por reinscribir estas características particulares en el contexto económico general descrito en el primer capítulo, en aras de un mejor entendimiento de la cuestión y de poder trazar con claridad las posibles tendencias futuras y los límites que plantea este modelo de economía.

Estos límites y tendencias se dibujan a lo largo del tercer capítulo, dividido en tres secciones: tendencias, desafíos y futuros.

Como tendencia, parece claro que la introducción de las plataformas digitales no revoluciona la economía global, sino que más bien supone una continuidad histórica respecto de lógicas anteriores, que el análisis de big data y las tecnologías digitales perfeccionan. La tercerización y el desmantelamiento de los sistemas de protección 
laboral, por ejemplo, se han convertido en la norma del capitalismo de plataformas. El que las plataformas digitales estén revolucionando el capitalismo, eliminando sus externalidades más negativas, no está nada claro.

Esta situación señala claramente los límites y los desafíos que debe enfrentar esta nueva modalidad de capitalismo. En el plano analógico, la introducción del análisis de big data para mejorar los procesos productivos industriales no resuelve el problema de la sobreproducción de las manufacturas y sus costes medioambientales asociados, solo los profundiza. En el plano digital la tendencia al monopolio y la necesidad de buscar nuevas fuentes de datos puede llevar al escenario de una red fragmentada en microrredes corporativas y métodos de recolección de datos que convierten la privacidad de las personas en una fantasía. Es más, ciertos modelos de plataformas, las más vinculadas a la "economía colaborativa", tienen un futuro muy incierto. La radicalización de la tendencia a tercerizar actividades resulta tremendamente ineficiente en términos económicos, teniendo que buscar la rentabilidad en perjuicio del factor trabajo, con trabajadores en condiciones de hiperexplotación, más que en la supuesta introducción de tecnologías punteras. Es razonable pensar que este tipo de plataformas dependan más de la existencia de capital excedente más que de la creatividad de sus CEO's.

Quizá el mayor mérito de Srnicek sea haber planteado de manera tan clara y concisa el panorama actual en relación a los nuevos modelos de economía sin perder casi rigor argumentativo. No obstante, el libro no deja de tener una clara orientación divulgativa, que desarrolla al mínimo algunas cuestiones que pueden dar para análisis tremendamente exhaustivos. Aun así, es capaz de dibujar en apenas 130 páginas un excelente estado de la cuestión, así como varias observaciones precisas acerca de los límites más inmediatos a los que se enfrenta el capitalismo de plataformas. En ese sentido puede ser una excelente puerta de entrada al campo del análisis de la economía digital, que puede ser desarrollado posteriormente. No obstante, quizás se eche de menos un desarrollo más contundente de las oportunidades de intervención pública en la economía de los datos apenas esbozadas en las últimas páginas. Uno no deja de sospechar que se cae en la repetición de ciertos lugares comunes acerca de las posibilidades de gestión colectiva de la economía; aunque es cierto que ese es un tema que da para varios libros.

Alejandro Pérez Lozano Universidad Complutense de Madrid (España) E-mail: alejap05@ucm.es 